Revista de Economia Política, vol. 38, no 3 (152), pp. 489-509, julho-setembro/2018

\title{
Revisitando o debate inercialista da inflação brasileira
}

\author{
Revisiting the inercialist debate of Brazilian inflation
}

HUGO CARCANHOLO IASCO PEREIRA* MARCELO LUIZ CURADO**+

\begin{abstract}
RESUMO: O objetivo deste artigo foi investigar as teorias da inflação inercial representadas pelas versões dos autores da PUC-RJ e da FGV-SP em uma perspectiva comparada, enfatizando os elementos teóricos comuns e como isto se materializou nas propostas de estabilização para a economia brasileira. Embora exista um background comum às teorias, com rigor analítico, elas são substancialmente diferentes, constituindo estratégias de estabilização bastante díspares. Concluiu-se que o inercialismo não pode ser considerado um corpo teórico uniforme, sobretudo no tocante a ruptura com a ortodoxia e a concepção monetária, conflito distributivo e plano de estabilização e o imperativo de neutralidade distributiva.

PALAVRAS-CHAVE: Teorias da Inflação Inercial; Perspectiva Comparada e História do Pensamento Econômico.
\end{abstract}

ABSTRACT: The aim of this paper was to investigate the inertial inflation's theory represented by the versions of economists from PUC-RJ and FGV-SP, emphasizing the theoretical elements present in each and how it materialized in the stabilization proposals for the Brazilian economy. Although there is a common background, the theories are substantially different. The conclusions suggested that the inercialist theories can't be considered a uniform theoretical framework, especially with respect to break with orthodoxy and monetary conception, distributive conflict and stabilization's plan and the necessity of neutrality distributive.

KEYWORDS: Inertial Inflation's Theory; Comparative Perspective and Economics' Thought History.

JEL Classification: B0; B22.

\footnotetext{
* Doutorando em Economia pelo CEDEPLAR-UFMG, MG - Brasil. Email: hclpereira@cedeplar.ufmg.br.

** Professor do Departamento de Economia e do Programa de Pós-Graduação em Desenvolvimento Econômico da UFPR, PR - Brasil. E-mail: curado@ufpr.br. Submetido: 16/Novembro/2016; Aprovado: 21/Dezembro/2017.

$+\mathrm{O}$ autor agradece o apoio do CNPq.
} 


\section{INTRODUÇÃO}

A teoria da inflação inercial surge no contexto da década de 1980, período no qual a política econômica ortodoxa mostrou-se ineficiente para a estabilização da economia brasileira. O inercialismo propôs explicações novas e políticas econômicas anti-inflacionárias que não estavam presentes no mainstream da ciência econômica ${ }^{1}$. Uma interpretação generalista, como Castro (2005) e Modiano (1990), sem se a atentar para as especificidades de cada autor inercialista, sugere que a inflação é o resultado do conflito distributivo entre os agentes econômicos na tentativa de manter a respectiva parcela de renda real. Neste sentido, as propostas inercialistas para estabilizar a economia brasileira indicavam a necessidade de desindexação com o imperativo de gerar um novo status quo econômico em que a nova distribuição de renda fosse idêntica à da velha economia inflacionada.

$\mathrm{O}$ modus operandi da política econômica diferia essencialmente entre as três propostas inercialistas. Enquanto havia um alinhamento entre as propostas de Francisco Lopes e de Luiz Carlos Bresser-Pereira e Yoshiaki Nakano em torno da necessidade de um Choque Heterodoxo, ou de um congelamento de preços, André Lara Resende e Pérsio Arida defendiam uma reforma monetária para eliminar a indexação, a Moeda Indexada. Argumenta-se que as versões inercialistas de Francisco Lopes, Luiz Carlos Bresser-Pereira e Yoshiaki Nakano, e André Lara Resende e Pérsio Arida apresentam um background teórico em comum, mas ao mesmo tempo possuem especificidades que não permitem pensá-las como uma unidade teórica homogênea.

O objetivo do presente artigo é discutir as diferentes concepções teóricas dos economistas inercialistas e os correspondentes desdobramentos em termos de política econômica para estabilizar a economia brasileira. Enfatizar-se-ão as diferenças teóricas e como isto se reflete nas formulações dos planos de estabilização. Para tanto, o artigo está dividido em quatro seções. A primeira foi dedicada à discussão do inercialismo de Francisco Lopes e a sua proposta de Choque Heterodoxo. As ideias de Bresser-Pereira e Nakano foram discutidas na segunda seção, ao passo que o inercialismo e a reforma monetária de Lara Resende e Arida foram desenvolvidos na terceira parte. A quarta seção foi desenvolvida para discutir os argumentos inercialistas mostrando os elementos em comum e as diferenças entre as três abordagens. As considerações finais foram apresentadas na última seção.

\footnotetext{
${ }^{1}$ Diversos autores (Arida e Lara Resende, 1985b; Bresser-Pereira e Nakano, 1984a; Lopes, 1985; Parkin, 1991) sugerem que o estado da arte da ciência econômica brasileira da década de 1980 condizia com a explicação monetarista baseada na versão aceleracionista da curva de Phillips, que além de considerar o trade-off entre desemprego e inflação considerava também as expectativas dos agentes acerca da variação dos preços na versão adaptativa. Surgiram análises dentro deste escopo teórico tentando estimar a curva aceleracionista de Phillips para a inflação brasileira do início da década de 1980, tal como Contador (1985), Lemgruber (1980) e Lopes (1982). O debate econômico se pautava na aplicabilidade da curva de Phillips à economia brasileira.
} 


\section{O CHOQUE HETERODOXO DE FRANCISCO LOPES}

O ponto de partida da discussão de Lopes (1985) foi a diferenciação entre o choque e a tendência inflacionária. Os choques inflacionários (ou deflacionários) correspondem à tentativa de alteração dos preços relativos por parte dos agentes econômicos. Supondo que o impacto dos choques inflacionários seja integralmente mensurado, a tendência inflacionária seria justamente o resíduo não explicado. Francisco Lopes rejeitou os argumentos ortodoxos que explicavam a tendência inflacionária enfatizando o componente expectacional dos agentes sobre a trajetória futura das variáveis macroeconômicas, desenvolvendo a teoria da inflação inercial, que considerava como vetor gerador da tendência inflacionária o “[...] padrão rígido de comportamento dos agentes econômicos em economias cronicamente inflacionadas" (Lopes, 1985, p. 136). Sem a presença de choques inflacionários, a trajetória presente da inflação seria conjugada às taxas pretéritas de variação dos preços:

A ideia básica é que num ambiente cronicamente inflacionário, os agentes econômicos desenvolvem um comportamento cronicamente inflacionário, os agentes econômicos desenvolvem um comportamento fortemente defensivo na formação de preços, o qual em condições normais consiste na tentativa de recompor o pico anterior de renda real no momento de cada reajuste periódico de preço. Quando todos os agentes adotam esta estratégia de recomposição periódica dos picos, a taxa de inflação existente no sistema tende a se perpetuar: a tendência inflacionária torna-se igual à inflação passada (Lopes, 1985, p. 137).

Em um modelo em que há a suposição de periodicidade do reajuste das rendas nominais, renda real máxima e taxa de variação de preços constantes. $\mathrm{O}$ valor máximo da renda real ou o valor de pico diminui à corresponde taxa de inflação do período atingindo o valor mínimo da renda real ao fim do período de reajuste, momento este em que o salário real é recomposto ao nível do pico. A renda real média depende, portanto, positivamente do pico de recomposição do salário real e da redução do período de recomposição salarial, e negativamente da taxa de inflação. Quanto maior a pressão social dos agentes econômicos pela elevação dos picos de renda real e pela redução da periodicidade do reajuste da renda nominal, maior é a taxa de variação dos preços. "Numa economia fortemente indexada, os preços sobem em resposta a aumentos de custos, e os custos sobem em resposta a aumentos de preços, ou seja, a inflação tende a se autossustentar" (Lopes, 1983a, p. 111). Argumentos como estes sustentam a proposição paradoxal de que a causa da inflação seria ela mesma:

[...] em qualquer economia cronicamente inflacionada, a principal causa da inflação é a própria inflação. Num regime de alta de inflação, os agentes econômicos são obrigados a desenvolver mecanismos para tentar 
defender suas rendas reais. Isto significa indexar da melhor maneira possível o preço da mercadoria que vende (que pode inclusive ser o trabalho) a uma média dos preços das mercadorias que compra (que no caso do trabalhador é o índice do custo de vida) (Lopes, 1983b, pp. 110-111).

Lopes (1983b) advoga que o comportamento defensivo dos agentes econômicos representa um equilíbrio inflacionário ao redor da taxa de inflação vigente, que se modifica, isto é, se acelera, caso haja um desalinhamento dos preços relativos da economia. No escopo teórico inercialista de Francisco Lopes, a inflação é o vetor resultante do conflito distributivo dos agentes econômicos pela renda nacional. A inflação é o modo pelo qual a economia se adéqua à incompatibilidade distributiva da renda nominal entre os diversos agentes econômicos em torno de determinada média das rendas reais. Segue trecho do autor sobre a incompatibilidade distributiva e a inflação, introduzindo a problemática de uma estratégia desinflacionária satisfatória com neutralidade distributiva:

A inflação crônica é fundamentalmente um mecanismo de compatibilização distributiva do sistema econômico. Ela transforma rendas nominais incompatíveis em rendas reais médias compatíveis com o produto nacional. O problema central da desinflação é como conseguir a recompatibilização distributiva num ambiente de estabilidade de preços. Em particular é fundamental que o próprio processo de desinflação não introduza novas tensões distributivas na economia (Lopes, 1984a, p. 144).

Em um processo inflacionário todos os preços e rendimentos nominais aumentam, contudo a velocidade de crescimento dos preços dos setores com periodicidade de reajuste fixo (aluguéis e salários, por exemplo) é menor que a velocidade de ajustamento dos setores com reajuste automático (no caso da economia brasileira, com base na ORTN). Este diferencial de velocidade dos reajustes nominais provoca uma transferência de renda real entre os agentes, a inflação está relacionada com a velocidade em que se dá a transferência de renda entre os agentes (Lopes, 1976).

A inflação, como um mecanismo de transferência de renda, gera ineficiência alocativa dos recursos porque os agentes procurarão estabelecer os seus recursos em setores nos quais a velocidade de ajustamento dos rendimentos nominais é alta, assim, os empresários não investirão em atividades de longo e médio prazo e os trabalhadores se estabelecem preferencialmente em setores com sindicatos fortes e politicamente ativos (Lopes, 1976). Por outro lado, uma inflação neutra corresponde à situação econômica em que não existam distorções como esta, ou que não aconteça a dinâmica redistributiva de renda entre os agentes, de modo que a distribuição de renda seja compatível com o vetor da média das rendas reais (Lopes, 1976).

Ao considerar uma economia hipotética simplificada com apenas dois agentes econômicos (A e B) com as respectivas rendas reais $\left(\mathrm{v}_{\mathrm{a}}\right.$ e $\left.\mathrm{v}_{\mathrm{b}}\right)$ e uma estrutura de reajuste da renda nominal totalmente defasada, como a Figura 1 ilustra, temos que, como a renda real do agente A estaria relativamente próxima do pico e a do B em 
um limiar fronteiriço ao vale, um congelamento dos preços e das rendas no dia D provocaria distorções distributivas insustentáveis da renda real entre os agentes A e B. O congelamento criaria descontentamento daquele cujo rendimento real estivesse abaixo da média, de modo que fosse obrigado a aumentar seus preços, defendendo, assim, a sua renda relativa. O objetivo do Choque Heterodoxo seria mitigar as consequências reais da adoção do congelamento, e logo da variação de preços nula, em uma economia com defasagem estrutural dos preços relativos.

Figura 1: Salário Real, Inflação e Congelamento no dia D

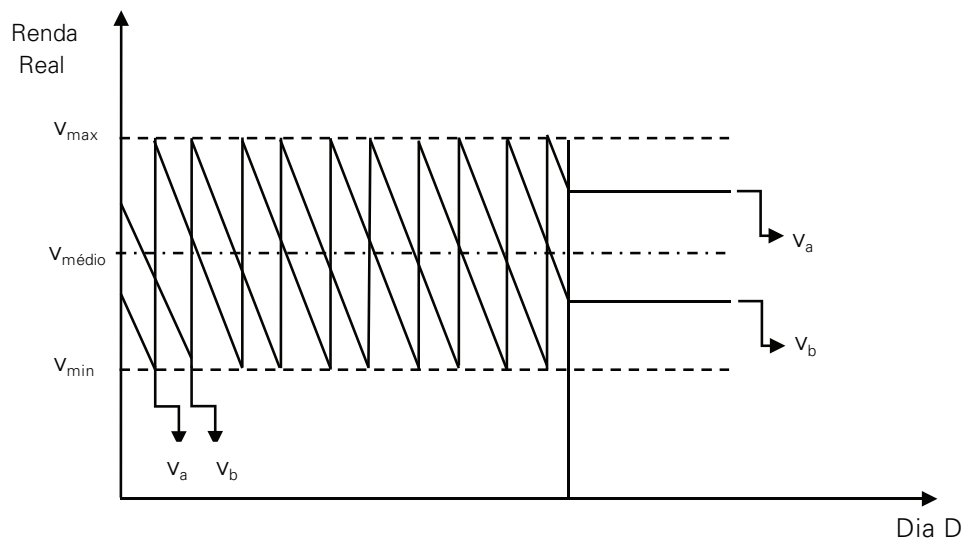

Fonte: Elaboração do autor com base em Lopes (1985).

O objetivo do Choque Heterodoxo foi conduzir a estrutura de reajustes periódicos da economia à média das rendas reais dos agentes econômicos através do congelamento pleno dos preços, imperando o princípio da neutralidade distributiva após o fim da indexação. Lopes (1985) sugeriu que as distorções de rendas causadas pelo congelamento de preços seriam suavizadas caso o governo adotasse medidas para ressincronizar os períodos de ajuste da renda nominal dos agentes (o que seria impossível para a renda da economia em sua totalidade, porém o autor defendeu que seria relevante pelo menos para os salários e preços administrados). Conforme a ilustração da Figura 2, tal medida se reduziria à submissão do reajuste das rendas dos indivíduos A e B à mesma sincronização de reajuste no dia S-D, com redução do pico e do vale de renda real. A partir deste dia as rendas seriam reajustadas a mesma taxa e periodicidade. $\mathrm{O}$ congelamento no dia $\mathrm{D}$ seria realizado pela média das rendas dos agentes A e B, o Choque Heterodoxo estancaria o elemento central da tendência inflacionária apontado pela teoria inercial. A indexação, e, por conseguinte, a inflação se dissiparia.

O Choque Heterodoxo duraria dois anos e seria dividido em duas etapas, sendo conduzido com políticas fiscal e monetária ativas. Ele seria conduzido da seguinte maneira: na primeira parte (nos seis meses iniciais) haveria o congelamento total e temporário dos preços das empresas públicas e dos produtos industriali- 
Figura 2: Salário Real, Inflação e Congelamento no dia D-II

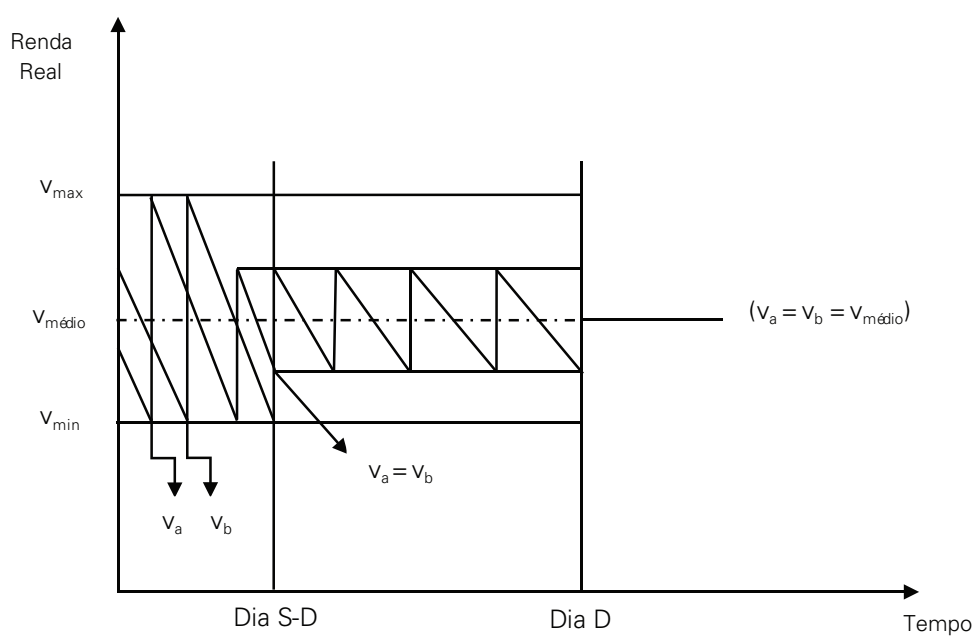

Fonte: Elaboração do autor com base em Lopes (1985).

zados pela $\mathrm{CIP}^{2}$ (Controle Interministerial de Preços). Os salários sofreriam um reajuste mensal da ordem de $0,5 \%$. Na segunda parte, os preços controlados pela CIP seriam reajustados em no máximo $1,5 \%$ ao mês. A livre negociação salarial seria instituída. A política cambial promoveria a valorização do câmbio com vistas a administrar os preços nacionais cotados em dólar. As políticas fiscal e monetária se concentrariam na promoção do crescimento econômico através da variável investimento público. Além disto, o Governo utilizaria uma política de subsídios para combater a distorção de preços dos setores afetados.

\section{O CONTROLE ADMINISTRATIVO DOS PREÇOS E RENDAS DE BRESSER-PEREIRA E NAKANO}

Bresser-Pereira e Nakano (1984a) partem de duas hipóteses básicas; os trabalhadores, empresários e rentistas possuem mecanismos pelos quais podem defender

\footnotetext{
${ }^{2}$ O período entre 1968 e 1973 é denominado como milagre econômico por apresentar taxas de crescimento econômico sem precedentes, com significativa redução da inflação. A média das taxas de crescimento do produto real foi $11,15 \%$ ao ano, enquanto a taxa de inflação permaneceu no menor patamar até o período pós-Real. A combinação de crescimento econômico com expressiva redução da taxa de inflação foi resultado do entendimento de que a inflação brasileira era resultado uma "inflação de custos", o que pautou a criação da Comissão Interministerial de Preços (CIP) para controlar os preços das empresas oligopolistas e monopolistas, com base na variação dos seus custos. Para Bresser-Pereira (1980), o ministro da Fazenda Delfim Netto adotou este diagnóstico inflacionário e o consequente mecanismo de controle de preços se baseando no livro de Ignácio Rangel de 1963 A Inflação Brasileira, fugindo das interpretações ortodoxas do governo Castelo Branco.
} 
a sua parcela da renda real relativa (a indexação formal e informal); e os agentes são resistentes às políticas econômicas recessivas, exigindo taxas satisfatórias de crescimento econômico.

Os fatores aceleradores da inflação decorrem do aumento relativo da renda dos trabalhadores ou capitalistas, isto é, dos aumentos salariais, das margens de lucros, desvalorização do câmbio real e dos insumos importados acima da variação da produtividade, ou do nível geral de preços. Aceleração a qual, segundo os autores, poderia ter sido causada de acordo com as seguintes situações inflação keynesiana, inflação estrutural, inflação administrada e redução da produtividade da economia.

No caso da inflação keynesiana, a demanda da economia como um todo é maior que a oferta, de modo que o sistema econômico esteja em pleno emprego. Neste caso todos os preços aumentam ao mesmo tempo, não existindo uma defasagem temporal dos reajustes relativos da renda, o que não se caracteriza, portanto, como um conflito distributivo (Bresser-Pereira e Nakano, 1984a). Caso este que é diferente da inflação estrutural e da administrada, porque o aumento de preços relativos setoriais seria propagado para a economia em razão do conflito distributivo. O aumento autônomo dos preços em relação à demanda agregada, no caso da inflação administrada, dependeria da existência de uma estrutura de mercado oligopolizada ou monopolizada e do poder de determinação dos salários pelos sindicatos. A microfundamentação da ascensão inflacionária, em um contexto de desaceleração cíclica com desemprego e capacidade ociosa, pode ser vista nesta citação ${ }^{3}$ :

Para manter a taxa de lucro (lucro sobre capital), as empresas do setor oligopolista tenderão a aumentar suas margens de lucro nos períodos de recessão. Dessa forma, a queda nas vendas é compensada pelos aumentos da margem, buscando-se manter o volume de lucro e a taxa de lucro (Bresser-Pereira e Nakano, 1984a, p. 9).

Os autores ressaltam que existem mecanismos mantenedores, perpetuadores autônomos do processo inflacionário ensejados pelos fatores aceleradores, isto é, a indexação formal e informal, o que é consequência da tentativa de os agentes econômicos manterem a renda real relativa constante ou resultado do conflito distributivo, tal que:

O fator mantenedor do patamar de inflação por excelência é o conflito distributivo, ou seja, o fato de que as diversas empresas e sindicatos dispõem de instrumentos econômicos e políticos para manter sua participação relativa na renda. Dado que, em um determinado patamar de inflação, os preços das diversas mercadorias e da força de trabalho tendem a variar com defasagens entre si, e porque os preços de uns são custos dos outros,

\footnotetext{
${ }^{3}$ Cabe ressaltar que Bresser-Pereira e Nakano (1984a) utilizaram a ideia de inflação administrada de Ignácio Rangel (1963), isto é, a ideia de que as empresas oligopolistas aumentam os preços na tentativa de manter a margem de lucro em um contexto de recessão econômica.
} 
os aumentos subsequentes de preços mercadorias e salários tenderão a ocorrer quase automaticamente (Bresser-Pereira e Nakano, 1984a, p. 10).

À medida que a correção monetária das margens de lucro e salários nominais fosse maior que a inflação corrente, a indexação passaria a atuar como um mecanismo de aceleração inflacionária. Quer dizer, os fatores mantenedores refletem o conflito distributivo, ao passo que mantém a parcela relativa da renda constante. Entretanto, a partir do instante em que alguns agentes econômicos, insatisfeitos com a parcela de renda real destinada desejam aumentá-la agressivamente, a indexação, ou o conflito distributivo, atua como um fator acelerador. Uma expansão autônoma da margem de lucros ou dos salários, em uma economia plenamente indexada, engendra uma espiral inflacionária com efeito multiplicador dos preços, proporcional àquela variação, ou igual à unidade, mantendo um novo patamar de inflação da economia, com a distribuição de renda original. Dinâmica a qual não ocorre em economias com indexação parcial, pois o multiplicador dos preços seria menor que um, de maneira que os agentes econômicos não conseguiriam manter a sua renda real relativa.

O fator sancionador da inflação é a expansão da oferta monetária. Embora Bresser-Pereira e Nakano (1984a) admitam a existência de expressiva correlação entre a expansão monetária e a ascensão inflacionária, os autores questionam o sentido da causalidade da equação fundamental de trocas, base do monetarismo. Bresser-Pereira e Nakano (1984a) advogam que não é a expansão monetária acima da taxa de crescimento do produto nominal que gera a inflação, mas sim que a variação do nível geral de preços da economia determina a expansão monetária. Nestes termos, a moeda é tratada de forma endógena. Uma expansão monetária só gera inflação a partir do instante em que a economia se encontra em pleno emprego e a demanda efetiva ultrapasse de fato a oferta agregada. Dinâmica esta que é induzida pela variável investimento, em resposta à redução da taxa de juros (caso da inflação keynesiana). No entanto, se as características estruturais desta expansão da oferta de moeda surgissem na situação em que apenas alguns setores produtivos estivessem próximos do pleno emprego, haveria uma espiral inflacionária através do conflito distributivo entre os agentes (inflação estrutural).

Em uma economia com aceleração inflacionária persistente e crônica, a expansão monetária e o déficit público não são as causas primárias da inflação, mas as consequências. Pois, dada a assunção de que os agentes econômicos são resistentes às políticas econômicas recessivas, o processo inflacionário tende a reduzir a quantidade real de moeda, conduzindo a economia à crise de liquidez, consequentemente à desaceleração e, logo, à recessão. A situação descrita levaria o sistema financeiro a recompor o nível monetário nominal anterior, expandindo a oferta monetária. Estes argumentos são essenciais para entender a endogeneidade da moeda ${ }^{4}$ e do déficit

\footnotetext{
${ }^{4}$ Moreno e Modenesi (2014) defendem que a endogeneidade monetária presente em Bresser-Pereira e Nakano (1984a) é oriunda da forte influência de Ignácio Rangel. Bresser-Pereira e Nakano (1996), por
} 
público para Bresser-Pereira e Nakano (1984a). Além do mais, os autores acreditam que as contas públicas deficitárias sancionariam a inflação vigente por meio da expansão monetária. Analogamente, o déficit público na forma de aumento dos gastos ou de redução dos impostos se torna uma fonte de inflação apenas se sobrepujar a demanda efetiva em relação à oferta agregada de pleno emprego.

A política econômica anti-inflacionária elaborada pelos autores sugere que a queda do patamar inflacionário aconteceria sem se concentrar exclusivamente na taxa de variação salarial, como insinua o trade-off da curva de Phillips, devendo-se considerar, portanto, o fato que de as margens de lucro não são fixas. Para Bresser-Pereira e Nakano (1984b) as empresas oligopolistas controlam as margens de lucro de acordo com a fase do ciclo econômico, conduzindo a economia a um cenário em que o desemprego, a capacidade ociosa e a inflação administrada aconteceriam concomitantemente, ocasionando a concentração da renda real a favor das empresas oligopolistas, isto é:

Nada impediria que neste modelo fosse também estabelecida uma relação direta entre variação na taxa de inflação, p, e a variação nas margens de lucro, m. Torna-se difícil, entretanto, estabelecer esta relação já que as margens de lucro, ao contrário do desemprego, não estão relacionadas necessariamente com a demanda agregada. Em princípio é de se esperar que, reduzindo-se a demanda agregada, as empresas reduzam suas margens de lucro, da mesma forma que os trabalhadores reduzam seus salários. Mas é sabido que as empresas oligopolistas tendem a fazer o inverso (Bresser-Pereira e Nakano, 1984b, p. 109).

A proposta de estabilização Política Administrativa de Preços e Rendas tinha por objetivo diminuir a inflação sem agravar a recessão da economia brasileira, ou causar efeitos perversos em termos de renda real aos trabalhadores e empresas de setores competitivos, em outras palavras, sem gerar desequilíbrios distributivos. Em um primeiro instante a economia seria estimulada através de política monetária expansionista, reduzindo a taxa de juros e aumentando o investimento. O efeito anti-inflacionário adviria da redução do custo de pagamento dos juros das empresas e do aumento das vendas das unidades oligopolistas, o que lhes propiciaria encolher as margens de lucro sem interferir na taxa de lucro corrente ${ }^{5}$. A operacionalização da política pode ser compreendida conforme os autores:

sua vez, reconheceram a utilização da ideias sobre endogeneidade monetária de Rangel (1963) para inverter a lógica da equação fundamental de trocas, tal como a ideia de inflação autônoma.

\footnotetext{
${ }^{5}$ Deve-se ressaltar que para Bresser-Pereira e Nakano (1984a) existe uma relação negativa entre o ciclo econômico e o nível de preços das empresas oligopolistas. Quando a economia está crescendo (fase de ascensão do ciclo), as empresas oligopolistas aceitam reduzir seus preços via competição com outras empresas oligopolistas, dado que o volume de vendas aumentou, isto significa manter uma taxa "normal" de lucro. Mas, quando a economia está com taxas de crescimento declinantes tendendo à recessão (fase de declínio do ciclo), as empresas oligopolistas aumentam seus preços, dado que o volume de vendas caiu, isso significa manter a taxa "normal" de lucro. Bresser-Pereira e Nakano (1984a) argumentam que
} 
Para operacionalizar essa estratégia os instrumentos fundamentais são os controles administrativos de preços e a desindexação planejada da economia. Concomitantemente será necessário reduzir gradualmente o déficit público real e o aumento da quantidade de moeda, de forma que toda a economia se ajuste a patamares de inflação progressivamente mais baixos (Bresser-Pereira e Nakano, 1984b, p. 115).

De acordo com o diagnóstico da inflação administrada ou autônoma, o controle dos preços e das rendas tangenciaria aqueles praticados pelos setores oligopolistas, procurando criar um resultado caso o mercado fosse competitivo. A etapa procedente seria a redução da emissão monetária e do déficit público real à medida que a inflação diminua. No modelo de inflação de Bresser-Pereira e Nakano (1984b) isto significaria reduzir a inflação através do congelamento da variável aceleradora (a margem de lucro das empresas oligopolistas) e, por conseguinte, dos fatores sancionadores da inflação. Contudo, os autores ressaltam que uma política anti-inflacionária adequada deveria se importar com o fator mantenedor da inflação:

[...] o caráter formal ou informalmente indexado da economia, ou, em outras palavras, a capacidade que os agentes econômicos têm de repassar aumentos de custos para preços independentemente de existência de pressão de demanda (Bresser-Pereira e Nakano, 1984b, p. 117).

A desindexação planejada e gradual da economia, de todos os setores oligopolistas, competitivos e ativos financeiros, conforme defendem os autores, deveria contemplar parcialmente a inflação passada, $\dot{p}$ e uma projeção declinante de inflação futura, $\dot{p}_{f}$, considerando as variações da produtividade setorial, de modo a manter o preço real médio constante. Na prática, devido à dificuldade de controlar os preços do grande número de empresas competitivas e que os mecanismos de mercados abarcam "[...] basta controlar os preços - e portanto as margens de lucro - das empresas oligopolistas e de alguns produtos essenciais" (Bresser-Pereira e Nakano, 1984b, p. 120). A desindexação da economia corresponderia à indexação da economia, do controle administrativo de preços, com base na previsão de inflação futura declinante.

as políticas econômicas baseadas na curva de Phillips se concentram apenas nos parâmetros dos salários nominais para controlar a inflação no ciclo econômico. No entanto, Bresser-Pereira e Nakano (1984a) sugerem que as margens de lucro das empresas não são fixas ao longo do ciclo econômico. Pelo contrário, elas se alteram à medida que o volume de vendas se altera. A alteração do nível de preços advém da tentativa de manutenção de uma taxa "normal" de lucro. Com isto, reduzir a taxa de juros aumentaria os lucros das empresas porque o custo com o pagamento de juros diminuiria e, por outro lado, a economia sairia da recessão e o volume de vendas aumentaria, ensejando tal dinâmica dos preços. 
O artigo de Arida e Lara Resende (1985) "Inertial Inflation and Monetary Reform in Brazil", exposto na conferência Inflation and Indexation do Institute of International Economics em dezembro de 1984, apresentou uma proposta de reforma monetária, a Moeda Indexada, batizada de Larida por Rudiger Dornbusch. Conforme os próprios autores, a sustentação teórica da característica inercial do processo inflacionário da proposta pode ser identificada nos trabalhos de Lara Resende (1979), Bacha e Lopes (1979), Arida (1982), Lopes e Modiano (1982), Lopes (1983), Arida e Lara Resende (1985a).

Arida e Lara Resende (1985b) refutaram o diagnóstico inflacionário monetarista para a inflação brasileira da década de 1980, ou os argumentos de que a rigidez nominal seria resultado da inadequação das políticas fiscais e monetárias, e que consequentemente apenas um choque ortodoxo com forte redução da base monetária através de política fiscal e monetária restritivas estancaria a inflação brasileira. Contudo, os autores não descartaram que as políticas econômicas ortodoxas diminuiriam a inflação comum, desconsiderando, no entanto, a eficácia destes mecanismos para combater a inflação crônica da economia brasileira com características peculiares, inerciais.

O artigo "Incompatibilidade Distributiva e Inflação Estrutural” de Lara Resende (1979) apresentou um modelo analítico para explicar o processo inflacionário a partir da concepção de que a inflação é resultado de um impasse social, do conflito distributivo simplificado em um setor industrial oligopolista e os sindicatos. O impasse social ocorreria no âmbito da repartição social do produto real nacional. Caso a soma das parcelas relativas da renda real desejada pelos agentes econômicos fosse maior que a possibilidade concreta, existiria um hiato de incompatibilidade ex ante da soma das rendas, conforme se identifica nesta citação:

[...] maiores taxas de crescimento industrial implicam em maior markup e, portanto, maior parcela de renda para o capital industrial. Por outro lado, sindicatos ativos, em luta por melhores salários, exigem uma parcela salarial que é incompatível com as exigências do capital industrial a estas taxas de crescimento. Está assim caracterizado o impasse que é resolvido através do uso feito pelo setor industrial oligopolizado do seu poder de fixação de preços. O resultado é um piso inflacionário proporcional ao hiato de incompatibilidade (Lara Resende, 1979, p. 24).

A determinação do salário nominal estabelece a parcela relativa da renda nominal dos trabalhadores e a das empresas oligopolistas. O setor industrial oligopolista ao manter o markup em relação aos custos, repassa as variações salariais para

\footnotetext{
${ }^{6}$ O trabalho de Arida e Lara Resende (1985b) pode ser considerado uma síntese das pesquisas individuais dos autores presentes em Lara Resende (1984a, 1984b) e Arida (1984).
} 
os preços das mercadorias, reduzindo o salário real através dos aumentos do nível geral de preços. O sistema econômico absorve a incompatibilidade distributiva ex ante, ou o hiato de incompatibilidade, através do aumento generalizado de preço em uma situação ex post. Lara Resende (1979) sugere que a dinâmica desta transferência de renda real entre os agentes pode ser identificada por meio da indexação salarial discreta com periodicidade fixa, que conduz a renda real dos trabalhadores à desvalorização permanente conforme a taxa de inflação vigente ou a um salário real menor que o compatível com a situação ex post. O pico salarial é recomposto ao término do período de reajuste com base na inflação passada, mas o salário real médio continuaria menor que o da situação ex post:

A inflação permite tornar compatíveis ex post demandas que são incompatíveis ex ante. Isto é possível porque o esquema de reajustes discretos dos salários não é capaz de isolar os salários reais dos efeitos da inflação. Em cada período, os salários reais sofrem a erosão causada pela alta de preços. O salário real pode ser trazido de volta ao seu nível almejado, ou negociado, ao final de cada período, mas o salário real médio será inferior ao almejado (Lara Resende, 1979, p. 9).

Os autores argumentam que a perfeita indexação se reproduz naturalmente nas hiperinflações através da redução da periodicidade dos reajustes contratuais. Nesta lógica de plena indexação da economia durante um processo hiperinflacionário, dois aspectos inter-relacionados são de grande importância na manutenção do nível da renda real dos agentes; o intervalo de reajuste e a taxa de inflação. Quanto maior a aceleração da variação do nível dos preços, menor a memória inflacionária do sistema econômico, o que realimenta a taxa de inflação. Isto acontece porque, em um contexto de aceleração inflacionária, os agentes antecipam os reajustes de seus preços para defender o respectivo nível de renda real. Logo, a antecipação do reajuste, ou a redução da memória inflacionária, aumentam a própria inflação ${ }^{7}$. O trecho abaixo esclarece este ponto:

A relação entre uma inflação crescente (que reduz o valor real dos contratos) e períodos de indexação mais curtos (que aumentam o valor real dos contratos) é crucial para a experiência brasileira. Ela mostra que

\footnotetext{
${ }^{7}$ A experiência das hiperinflações inspirou a proposta Larida (Modenesi, 2005), Arida e Lara Resende (1985b) notaram uma característica das hiperinflações clássicas que fora primordial para a Moeda Indexada, a redução da memória inflacionária do sistema econômico que se aproxima de zero à medida que a taxa de inflação possuísse uma trajetória explosiva ou tendesse ao infinito e, por conseguinte, eliminando a característica inercial da inflação. Levando os autores a reescrever Karl Marx: "As hiperinflações carregam em si mesmas as sementes de sua autodestruição na medida em que obrigam os agentes a reduzir o período do contrato" (Arida e Lara Resende, 1985b, p. 19). Em um dos textos basilares de Arida e Lara-Resende (1985b) “A Moeda Indexada: Nem Mágica Nem Panaceia” de Lara Resende (1984), André Lara Resende mostra conhecimento de causa sobre a hiperinflação húngara e sobre o pengo fiscal, referenciando a sua análise com base em Bloomberger e Makinen (1980, 1983).
} 
a indexação é uma resposta natural dos agentes nos processos de inflação inercial (Arida e Lara Resende, 1985b, p. 19).

A defasagem da taxa de inflação utilizada nos reajustes contratuais é o que os autores denominaram como a memória inflacionária do sistema econômico, “[...] é o período de indexação que comanda a memória do sistema econômico" (Arida e Lara Resende, 1985b, p. 18). A essência da inflação da teoria inercialista de André Lara Resende e Pérsio Arida é a reprodução da taxa de inflação pretérita através da indexação contratual, resultado da ação defensiva por parte dos agentes em relação à manutenção da participação relativa da respectiva renda real em relação à renda nacional.

O objetivo fundamental da reforma monetária presente na Moeda Indexada era atuar sob o principal parâmetro da inflação inercial, a memória inflacionária do sistema econômico, de modo a anulá-la, como acontece espontaneamente nas economias hiperinflacionadas. Isto aconteceria por meio da indexação integral da economia brasileira através da criação de uma moeda totalmente indexada com base na ORTN, o Novo Cruzado. Os autores ressaltam que tal efeito sob a memória inflacionária poderia ser lograda sem conduzir a economia ao estágio de hiperinflação:

Uma reforma monetária separa o efeito desejado - qual seja, a redução do período de indexação - de sua causa espontânea, a saber, a aceleração da inflação. A reforma monetária encolhe a memória do sistema econômico na ausência de uma hiperinflação (Arida e Lara Resende, 1985b, p. 19).

A formulação teórica da reforma monetária seria simples. A moeda da economia brasileira deixaria de ser o Cruzeiro, sendo substituída pelo Novo Cruzeiro em data pré-anunciada, além de integralmente indexada à ORTN com paridade fixa. Em um primeiro momento, os reajustes da ORTN seriam realizados de acordo com a inflação do Cruzeiro, o que determinaria, por sua vez, a equivalência entre o Cruzeiro e o Novo Cruzeiro. A conversão deveria ser feita livremente, considerando a equivalência diária entre as moedas. Os autores indicam que esta medida seria importante para que não gerasse inflação na nova moeda por meio do aumento da velocidade de circulação. Os salários, aluguéis e contratos seriam reajustados em Novo Cruzado, conjecturando a inflação média dos seis meses pretéritos.

A partir da emissão da nova moeda indexada, os depósitos à vista e a prazo, as transações do Banco Central, a poupança e os empréstimos seriam transacionados em Novo Cruzeiro. Os contratos que consideravam a ORTN como unidade de conta seriam transformados em Novo Cruzeiro, assim como os preços administrados pelo governo. O câmbio em Novo Cruzeiro seria mantido à taxa real anterior à reforma. À medida que o Novo Cruzeiro fosse largamente utilizado na economia brasileira, não haveria a necessidade de calcular a desvalorização do Cruzado, restando a opção de desvalorização ad infinitum em relação à nova moeda. A reforma 
monetária preconizada introduziria uma nova moeda, num contexto de memória inflacionária da economia nula, e, por conseguinte, a inflação inercial não existiria.

\section{A TEORIA INERCIALISTA EM UMA PERSPECTIVA COMPARADA}

No escopo teórico da inflação inercial é possível identificar uma divisão entre as especificidades da compreensão do objeto de estudo e a correspondente sugestão de política econômica anti-inflacionária. Procuraremos discutir e argumentar sobre o que pode ser considerado específico de cada versão do inercialismo nesta seção.

Para Francisco Lopes qualquer economia nacional exposta à inflação crônica desenvolve mecanismos econômicos de tal maneira a existir um processo inflacionário inercial. $\mathrm{Na}$ ausência de choques nos preços relativos, a taxa de variação de preços segue uma tendência, um movimento de inércia determinado pela inflação passada. Isto advém do comportamento defensivo dos agentes econômicos na formação de seus preços através da recomposição do pico da renda real com base na inflação acumulada. O movimento inercial da inflação reproduz as taxas pretéritas de variação de preços da economia à medida que os agentes defendem a respectiva parcela da renda no produto real. O conflito distributivo gera um vetor de equilíbrio da inflação ao redor da média das rendas reais. Choques ou as alterações dos preços relativos alteram o patamar inflacionário da economia, com uma situação de aceleração das taxas de variação dos preços.

Já no propósito inercialista de Luiz Carlos Bresser-Pereira e Yoshiaki Nakano, a inflação é o resultado do conflito distributivo entre os agentes econômicos da economia capitalista, mais especificamente da manutenção (fatores mantenedores) ou do aumento do nível real de renda relativo (fatores aceleradores). O movimento inercial da taxa de variação dos preços é explicado pelos fatores mantenedores da inflação. A indexação formal e a informal da economia permitem que os agentes mantenham as respectivas rendas relativas reais constantes ao passo que a indexação considera exatamente a inflação passada. A tendência inercial reprodutora das taxas de inflação pretérita se modifica para uma situação de aceleração inflacionária a partir do instante em que os agentes, insatisfeitos com a devida parcela relativa da renda real, indexam os seus preços acima da taxa de inflação passada. Os agentes que possuem a possibilidade de agir desta maneira pertencem a estruturas de mercado imperfeitas (oligopólios e os sindicatos).

Os autores argumentam que a margem de lucro das empresas oligopolistas respeita um padrão cíclico. Em um contexto de recessão econômica, a redução das receitas oriundas das vendas é compensada pelo aumento da margem de lucro, o que mantém o volume e a taxa de lucro. As variações da margem de lucro maiores a as da produtividade de um setor específico aumentam os custos para as outras empresas da cadeia produtiva, as quais são obrigadas a repassá-los aos preços para manter a margem de lucro. Os salários, as matérias-primas e os bens intermediários são, portanto, as vinculações fundamentais da propagação inflacionária ao se considerar o conflito distributivo da economia como um todo. Bresser-Pereira e 
Nakano (1984) inverteram a lógica da equação fundamental de trocas de trocas de modo que não é a expansão monetária em taxas acima do crescimento do produto nominal que geraria a inflação. Tal dinâmica ocorreria apenas em uma economia de pleno emprego, na qual a redução da taxa de juros aumentaria o investimento e, logo, a demanda agregada acima daquele ponto, criando uma situação de inflação de demanda.

O déficit público e a expansão monetária guardam um caráter endógeno em relação à variação geral de preços, porque, assumindo a hipótese que os agentes econômicos exigem taxas de crescimento do produto satisfatórias, o aumento da inflação reduz a quantidade real de moeda, gerando uma crise de liquidez, o que obriga o sistema financeiro a aumentar a quantidade de moeda, logo a variável monetária acompanha as variações da taxa de inflação.

$\mathrm{Na}$ teoria inercialista de André Lara Resende e Pérsio Arida a inflação é a consequência de um impasse social presente no conflito distributivo entre um setor industrial oligopolista e os sindicatos em torno da repartição social do produto real da economia. O hiato de incompatibilidade ex ante da soma das rendas desejadas pelos agentes seria solucionado pelo mecanismo inflacionário, que permitiria a compatibilidade ex post da distribuição da renda real. A indexação, e a consequente reprodução da inflação passada, permite certo grau de flexibilidade ao sistema econômico à medida que a distribuição da renda real se torna compatível com a média das rendas. Contudo, André Lara Resende e Pérsio Arida descartaram a ideia de que as estruturas de mercado imperfeitas são a causa da inflação.

As três estratégias de controle inflacionário estavam relacionadas com a desindexação plena da economia, com base em um novo status quo econômico no qual a nova distribuição de renda fosse idêntica à da velha economia inflacionada. Imperando a necessidade da neutralidade distributiva no combate à inflação. Nesta lógica, o modus operandi da política econômica difere essencialmente entre as três propostas. Há um alinhamento entre Francisco Lopes e Luiz Carlos Bresser-Pereira e Yoshiaki Nakano em torno da necessidade de um Choque Heterodoxo, ou de um congelamento de preços. Ao passo que André Lara Resende e Pérsio Arida defenderam uma reforma monetária para eliminar a indexação, a Moeda Indexada.

O objetivo do Choque Heterodoxo era ressincronizar a estrutura de reajuste dos preços indexados, visando à desindexação plena da economia brasileira. O que seria atingido através do congelamento de preços, conduzindo a distribuição da renda entre os agentes à própria média real, ou seja, com neutralidade distributiva em relação à economia inflacionada. Do contrário, os agentes descontentes elevariam seus preços para aumentar a parcela da renda relativa, criando uma espiral inflacionária.

A Política Administrativa de Preços e Rendas agiria sob os fatores básicos relacionados à taxa de inflação. Em um primeiro instante, a política monetária seria utilizada para estimular os investimentos, diminuindo a inflação através da redução dos custos (juros) e do aumento das vendas e a consequente retração da margem de lucros (sem interferir na taxa de lucro). O controle de preços seria implantado nos setores oligopolistas da economia, atingindo o fator acelerador da inflação (a margem 
de lucro destas empresas). À medida que a inflação diminuísse, o governo deveria reduzir a emissão monetária e o déficit público (o fator sancionador). A desindexação seria atingida pela indexação da economia, considerando uma taxa de inflação futura declinante, eliminando desta maneira a atuação dos fatores mantenedores.

A Moeda Indexada não tinha por objetivo redefinir a distribuição de renda, mas atuar para superar o impasse social que a indexação significava. As experiências históricas das hiperinflações indicaram que os agentes reduziam a periodicidade dos reajustes contratuais procurando a plena indexação de seus rendimentos. Este foi o elemento que conduziu o desaparecimento abrupto das hiperinflações. André Lara Resende e Pérsio Arida incorporam isto na Moeda Indexada, ao tentar reproduzir o efeito desejado das hiperinflações (zerar a memória inflacionária) para eliminar a inflação inercial.

A explicação dos economistas inercialistas para a inflação brasileira da década de 1980 fora notadamente pautada na ideia de que a inércia inflacionária é resultado da tentativa de os agentes manterem a respectiva parcela de renda real constante, ou seja, a reprodução das taxas de variação de preços no passado advém do conflito distributivo acerca do produto nacional. Não obstante, embora os três corpos teóricos inercialistas possuam elementos em comum, o que torna as conclusões parecidas. Rigorosamente, não podemos estabelecer que as teorias inercialistas sejam de fato homogêneas o ponto de permitir referir as mesmas como uma unidade teórica. Existem variantes analíticas nas versões desenvolvidas anteriormente, que ao serem consideradas mostram necessariamente que as teorias inercialistas são diferentes e não considerar este fato pode erroneamente levar à conclusão de que o inercialismo é um corpo teórico homogêneo. A seguir há uma tentativa de sistematização destes elementos teóricos.

\section{Concepção monetária e Ruptura com a Ortodoxia}

Os economistas inercialistas da PUC-RJ não romperam com o mainstream da ciência econômica. Não existem evidências teóricas nos trabalhos de Francisco Lopes, André Lara Resende e Pérsio Arida que sustente a refutação da teoria quantitativa da moeda ${ }^{8}$. O argumento dos autores era que as teorias macroeconômicas baseadas no trade-off entre taxa de desemprego e inflação e nas expectativas racionais não forneciam base analítica para compreender a real situação da economia brasileira da década de 1980. Esta seria uma situação excepcional. Ao contrário de Luiz Carlos Bresser-Pereira e Yoshiaki Nakano, que romperam com tal axioma básico da teoria mainstream. Os economistas da FGV-SP inverteram a lógica da teoria quantitativa da moeda, especificamente, é a taxa de inflação do sistema

\footnotetext{
${ }^{8}$ Nesta perspectiva de diferenciação entre ortodoxia e heterodoxia Amado (2000) e Mollo (1995) pautam seus argumentos entre as diferentes concepções de moeda na ciência econômica. Segundo os autores, os economistas ortodoxos pensam na moeda como neutra, determinada exogenamente pelo banco central. Os economistas heterodoxos tratam a moeda como endógena às atividades do sistema econômico.
} 
econômico que determina a expansão do estoque monetário, não o contrário. Assim, a moeda é considerada endógena no processo inflacionário, ao contrário do que propõe a macroeconomia monetarista.

\section{Conflito distributivo e o Imperativo de Neutralidade Distributiva das Propostas de Estabilização}

Tanto o inercialismo na versão dos autores da PUC-RJ quanto o da FGV-SP possuem o conflito distributivo como substrato analítico. Todavia, o argumento do primeiro grupo de economistas se constitui a nível microeconômico porque os agentes consideram a inflação passada ao reajustar seus preços e manter a distribuição de renda real da economia, sem perder, portanto, renda para outros setores. A indexação formal e informal dos preços é uma característica que os agentes incorporam naturalmente em uma situação de inflação crônica.

Nesta linha, Lara Resende (1984b) admite que a causa primária da inflação é o conflito distributivo, mas que "Se não forem adequadamente formuladas as razões do conflito distributivo, afirmar que a inflação decorre de demandas sobre a renda superior ao todo é uma observação meramente tautológica" (Lara Resende, 1984a, p. 8). A proposta Moeda Indexada não visava solucionar a incompatibilidade distributiva, ou modificar a estrutura social e política da economia brasileira. O objetivo era desindexar a economia, superando o impasse social que o processo inflacionário significava, e logo eliminar a inflação inercial por definição. "[...] a reforma da moeda indexada não tem pretensões de resolver todos os problemas fundamentais do país" (Lara Resende, 1984a, p. 9):

[...] é importante notar que a percepção do processo inflacionário como consequência de uma incompatibilidade distributiva não nos permite apontar os sindicatos ou os oligopólios como causadores da inflação. Em particular, deve-se rejeitar a visão parcial e distorcida a qual a inflação deve ser atribuída às pressões sindicalizada dos trabalhadores. Oligopólios e sindicatos são ambos violações do mundo da concorrência perfeita que dão ao processo inflacionário um caráter político. O controle da inflação está, portanto, associado à superação do impasse social que ela reflete (Lara Resende, 1979, p. 25).

Cabe notar que a teoria da inflação inercial dos economistas da PUC-RJ fora desenvolvida em contraposição à explicação mainstream de Sargent (1982) ${ }^{9}$. Lopes (1985) reinterpretou o fim abrupto das hiperinflações da Áustria entre 1921 e 1922

\footnotetext{
${ }^{9}$ Sargent (1982) analisou as experiências históricas de Hiperinflação do pós- Primeira Guerra Mundial da Áustria, Hungria, Alemanha e Polônia dentro do escopo teórico da macroeconomia das expectativas racionais. Thomas Sargent concluiu que o processo hiperinflacionário terminou em função da criação de um Banco Central independente que se mostrara efetivamente disposto a negar crédito para os respectivos governos e uma forte política fiscal restritiva. Estas medidas se mostraram com altíssima
} 
e da Alemanha entre 1922 e 1923; o autor conjecturou que em processos inflacionário como estes, os agentes, sob o comportamento defensivo característico de economias com inflação crônica (como o próprio sistema econômico brasileiro da década de 1980), substituem a moeda nacional pela estrangeira, o que provocaria a redução da periodicidade dos reajustes das rendas nominais em direção ao valor nulo. Isto ocasionaria a transgressão do pico da renda real para o valor médio em qualquer taxa de inflação. Como a distribuição de renda estabelecida seria determinada pelo padrão médio da renda real, a dessincronização e logo a inércia inflacionária desapareceriam. Arida e Lara Resende (1985b) notaram uma característica das hiperinflações clássicas que fora primordial para a Moeda Indexada, a redução da memória inflacionária do sistema econômico que se aproximaria de zero à medida que a taxa de inflação possuísse uma trajetória explosiva ou tendesse ao infinito e, por conseguinte, eliminando a característica inercial da inflação:

Esta condição fundamental é atendida nas hiperinflações. Um dos mistérios do término bem-sucedido das hiperinflações está em que, durante uma hiperinflação, todas as presumidas conveniências dos contratos de períodos longos são suplantadas pela necessidade de rever preços continuamente (Arida e Lara Resende, 1985b, p. 19).

Tanto Lopes (1985) quanto Arida e Lara Resende (1985b) desenvolveram um diagnóstico inercialista com elementos teóricos compatíveis com o modelo de inflação dos estruturalistas latino-americanos de Furtado (1957), Noyola (1957) e Sunkel $(1958)^{10}$. A ideia de que a tendência inflacionária é resultado do padrão rígido de comportamento dos agentes em economias com inflação crônica é a mesma lógica dos mecanismos de propagação inflacionária através dos quais os grupos sociais defenderiam o nível real relativo de renda, repassando os custos das pressões inflacionárias para seus preços. Há de ressaltar uma diferença bastante sutil, embora relevante. Os estruturalistas explicitam que os mecanismos de propagação são a expressão estrutural mais nítida do conflito distributivo acerca da repartição social do produto real da economia. Os inercialistas da PUC-RJ fornecem uma abordagem com fundamentação microeconômica para o comportamento dos agentes em economias cronicamente inflacionadas, apesar de não trabalhar com uma função maximizadora de utilidade.

Enquanto o inercialismo na versão PUC-RJ deu um caráter microeconômico natural aos processos crônicos de aceleração inflação. Com influência do pensamento de Ignácio Rangel, os economistas da FGV-SP argumentavam que o conflito dis-

credibilidade para o público de tal maneira a alterar as expectativas futuras de inflação, promovendo a reversão na formação de preços.

${ }^{10}$ A ideia que choques nos preços relativos da economia alterem a taxa de inflação está presente nos autores estruturalistas latino-americanos, no conceito de pressões inflacionárias, que se transformariam efetivamente em aceleração da variação do nível geral de preços através do funcionamento dos mecanismos de propagação inflacionária. 
tributivo é uma característica histórico-estrutural da economia capitalista. A formação de oligopólios nas economias modernas implica na ideia de inflação administrada destes autores. É o poder de mercado destes setores que gera a capacidade de aumentar os preços em um período de recessão para manter a taxa de lucro, o que gera o vetor de inércia inflacionária. Em suma, ambos os grupos de economistas utilizam a ideia de conflito distributivo na estrutura analítica. Mas Bresser-Pereira e Yoshiaki Nakano utilizam-na além da ideia de um processo inflacionário neutro.

As diferenças quanto à importância do conflito distributivo na concepção analítica de cada versão inercialista se consolidaram nas próprias estratégias de estabilização. As três propostas para estabilizar a economia brasileira na década de 1980 compreendiam a necessidade de manter o status quo da distribuição da renda real da economia inflacionada pós-estabilização. Entretanto, os diferentes diagnósticos inercialistas definiram necessariamente as diferentes características dos planos de estabilização.

A ênfase de Francisco Lopes na dessincronização da estrutura de indexação (e o consequente equilíbrio inflacionário ao redor da distribuição de renda real) está relacionada com a estratégia de congelar os preços no dia $\mathrm{D}$, e a partir desta data conduzir a economia à média da renda real dos agentes porque assim os agentes não teriam incentivos para reajustar seus preços. $\mathrm{O}$ controle administrativo de preços e renda, por sua vez, é justificado pelo diagnóstico de inflação administrada, através da qual os setores oligopolistas manteriam a taxa de lucro. Por isto controlar a margem de lucro dos mesmos (e logo da distribuição de renda da economia) seria fundamental. Já a percepção de que os processos inflacionários são caracterizados pela redução da memória inflacionária à medida que o sistema econômico se aproxime da situação extrema de hiperinflação conduziu André Lara Resende e Pérsio Arida a propor uma reforma monetária com a finalidade de desindexar a economia brasileira provocando uma hiperinflação controlada. O Quadro 1, abaixo, sintetiza a nossa discussão.

Quadro 1: Síntese Comparativa das Três Teorias Inercialistas

\begin{tabular}{|c|c|c|c|}
\hline & Choque Heterodoxo & $\begin{array}{c}\text { Controle } \\
\text { Administrativo }\end{array}$ & Moeda Indexada \\
\hline $\begin{array}{l}\text { Concepção } \\
\text { Monetária }\end{array}$ & Moeda Exógena & Moeda Endógena & Moeda Exógena \\
\hline $\begin{array}{l}\text { Conflito } \\
\text { Distributivo } \\
\text { e Inércia }\end{array}$ & $\begin{array}{l}\text { Ação natural dos } \\
\text { agentes em um } \\
\text { ambiente de inflação } \\
\text { crônica; fundamentação } \\
\text { microeconômica }\end{array}$ & $\begin{array}{l}\text { Resultado Histórico do } \\
\text { Capitalismo brasileiro }\end{array}$ & $\begin{array}{l}\text { Ação natural dos } \\
\text { agentes em um } \\
\text { ambiente de inflação } \\
\text { crônica; fundamentação } \\
\text { microeconômica }\end{array}$ \\
\hline $\begin{array}{l}\text { Neutralidade } \\
\text { Distributiva }\end{array}$ & $\begin{array}{l}\text { Congelamento } \\
\text { de preços com } \\
\text { desindexação planejada }\end{array}$ & $\begin{array}{l}\text { Congelamento de } \\
\text { preços com controle } \\
\text { do markup dos } \\
\text { setores oligopolistas e } \\
\text { desindexação planejada }\end{array}$ & $\begin{array}{l}\text { Hiperinflação controlada: } \\
\text { redução da memória } \\
\text { inflacionária }\end{array}$ \\
\hline
\end{tabular}

Fonte: Elaboração dos autores. 


\section{CONSIDERAÇÕES FINAIS}

O objetivo deste artigo foi investigar as teorias da inflação inercial representadas pelas versões dos autores da PUC-RJ e FGV-SP em uma perspectiva comparada, enfatizando os elementos teóricos presentes em cada uma e como isto se materializou nos planos de estabilização. Notou-se que as especificidades teóricas de cada versão estabelecem que, com rigor, não é possível identificar uma unidade teórica inercialista. Embora em uma visão generalista as três versões inercialistas sejam parecidas, detectamos elementos teóricos que as diferenciam substancialmente em três vertentes: ruptura com a ortodoxia e a concepção monetária, conflito distributivo e o imperativo de neutralidade distributiva no plano de estabilização.

\section{REFERÊNCIAS BIBLIOGRÁFICAS}

AMADO, A. M. Limites monetários ao crescimento: Keynes e a não-neutralidade da moeda. Ensaios FEE, v. 21, n. 1, p. 44-81, 2000.

ARIDA, P. Reajuste Salarial e Inflação. Pesquisa e Planejamento Econômico, v. 12, n. 2, p. 311-343, 1982.

ARIDA, P. Economic Stabilization in Brazil: Texto para discussão, n. 84, PUC-RJ, Rio de Janeiro RJ, 1984.

ARIDA, P. LARA RESENDE, A. Recessão e taxa de juros: O Brasil nos primórdios da década de 1980. Revista de Economia Política, v. 5, n. 1, p. 5-21, 1985a.

ARIDA, P. LARA RESENDE, A. (1985) Inertial Inflation and Monetary Reform in Brazil. Texto para Discussão, n. 63, PUC RJ, Rio de Janeiro RJ, 1985 b.

BACHA, E. L. LOPES, F. L. Inflation, Growth and Wage Policy: In Search of a Brazilian Paradigm: Texto para Discussão, n. 10, PUC RJ, Rio de Janeiro RJ, 1979.

Bresser-Pereira, L. C. As Contradições da Inflação brasileira. In: Encontros com a Civilização brasileira,

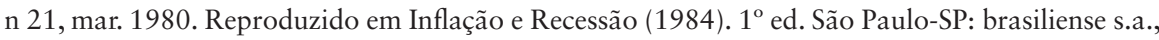
p. 105-31, 1980.

Bresser-Pereira, L. C., NAKANO, Y. Fatores Aceleradores, mantenedores e sancionadores da inflação. Revista de Economia Política, v. 4, n. 1, p. 5-22, 1984a.

Bresser-Pereira, L. C, NAKANO, Y. Política administrativa de Controle de Inflação. Revista de Economia Política, v. 4, n. 2, p. 105-124, 1984 b.

BRESSER-PEREIRA, L. C. A Inflação Decifrada. Revista de Economia Política, v. 16, n. 4, p. 20-36, 1996.

BLOOMBERGER, W. A.; MAKINEN, G. E. The Hungarian Hyperinflation and Stabilization of $1945-$ 1946. Journal of Political Economy, v. 91, n. 5, p. 801-824, 1983.

CARNEIRO, D. D. MODIANO, E. Ajuste Externo e Desequilíbrio Interno: 1980-1984. In: ABREU, M. P. (Ed.). A Ordem do Progresso. $1^{\circ}$ ed. Rio de Janeiro RJ. p. 323-344, 1990.

CASTRO, L. B. Esperança, Frustração e Aprendizado: A História da Nova República. In: GIAMBIAGI, F. VILLELA, BARROS DE CASTO, L. HERMANN, J. Economia brasileira Contemporânea. $1^{\circ}$ ed. Rio de Janeiro RJ,. p. 116-137, 2005.

CONTADOR, C. Reflexões sobre o dilema entre inflação e crescimento econômico na década de 80 . Pesquisa e Planejamento Econômico, v. 15, n. 1, p. 33-72, 1985.

FURTADO, C. Formação Econômica do Brasil. 34. ed. São Paulo-SP, 1957 (1 ${ }^{\circ}$ edição).

LARA RESENDE, A. Incompatibilidade Distributiva e Inflação Estrutural. Texto para discussão, n.1, PUC RJ, Rio de Janeiro RJ, 1979. 
LARA RESENDE, A. A Moeda Indexada: Nem Mágica nem Panacéia. Texto para discussão, n. 81, PUC RJ. Rio de Janeiro RJ, 1984a.

LARA RESENDE, A. A Moeda Indexada: Uma Proposta para Eliminar a Inflação Inercial. Texto para discussão, n. 75, PUC RJ. Rio de Janeiro RJ, 1984b.

LEMGRUBER, A. C. Expectativas racionais e o dilema produto real/inflação no Brasil. Pesquisa e Planejamento Econômico, v. 34, n. 4, p. 497-531, 1980.

LOPES, F. L. Inflação, correção monetária e controles de preços. Revista de Economia brasileira, v. 30, n. 4, p. 427-455, 1976.

LOPES, F. L. Inflação e nível de atividade no Brasil: um estudo econométrico. Pesquisa e Planejamento Econômico, v. 12, n. 3, p. 639-670, 1982.

LOPES, F. L. Entendendo a Inflação. In: LOPES, F. L. (Ed.). O Choque Heterodoxo: Combate à Inflação e Reforma Monetária. $1^{\circ}$ ed. Rio de Janeiro RJ. Campus. p. 110-111, 1983a.

LOPES, F. L. Política Salarial e Dinâmica do Salário Nominal. Pesquisa e Planejamento Econômico, v. 14, n. 2, p. 453-476, 1983 b.

LOPES, F. L. Reforma Monetária, Pacto Social e Desindexação. In: LOPES, F. (Ed.). O Choque Heterodoxo: Combate à Inflação e Reforma Monetária. $1^{\circ}$. ed. Rio de Janeiro RJ. Editora Campus, 1984a. p. 144-145, 1984a.

LOPES, F. L. Diretas-Já e a Economia Nacional. In: LOPES, F. L. (Ed.). O Choque Heterodoxo: Combate à Inflação e Reforma Monetária. $1^{\circ}$ ed. Rio de Janeiro-RJ. p. 116-117, 1984b.

LOPES, F. L. Inflação Inercial, Hiperinflação e Desinflação: Notas e Conjecturas. Revista de Economia Política, v. 5, n. 2, p. 135-151, 1985.

LOPES, F. L., MODIANO E. M. Indexação, Choque Externo e Nível de Atividade: Notas Sobre o Caso brasileiro, Texto para Discussão, n. 37, PUC RJ. Rio de Janeiro RJ, 1982.

MODENESI, A. de M. Regimes Monetários Teoria e a Experiência do Real. $1^{\circ}$. ed. Editora Manole Ltda. Barueri SP, 2005.

MODIANO, E. A Ópera dos Três Cruzados. In: ABREU, M. de P. (Ed.). A Ordem do Progresso. $1^{\circ}$ ed. Rio de Janeiro RJ, p. 347-385, 1990.

MORENO, O. P.; MODENESI, A. DE M. A curva de Rangel: origem, desenvolvimento e a formalização de Bresser-Pereira e Nakano. Revista de Economia Política, v. 34, n. 4, p. 565-586, 2014.

MOLLO, M. D. L. R. Ortodoxia e Heterodoxia Monetárias: a Questão da Neutralidade da Moeda. Revista de Economia Política, v. 24, n. 3, p. 323-344, 2004.

NOYOLA, J. F. La Evolución del Pensamiento Económico en el Último Cuarto de Siglo y su Influencia en la América Latina. El Trimestre Económico, v. 91, n. 3, p. 269-283, 1956.

PARKIN, V. Chronic Inflation in an Industrialising Economy: the Brazilian experience. $1^{\circ}$. ed. Cambridge University Press. New York NY, 1991.

RANGEL, I. A Inflação brasileira. $1^{\circ}$. ed. São Paulo-SP: brasiliense s.a., 1963.

SARGENT, T. The End of Four Big Inflations. In: HALL, R. (Ed.). Inflation: Causes and Effects. Chicago: University of Chicago Press, p. 41-98, 1982.

SUNKEL, O. A Inflação Chilena: Um Enfoque Heterodoxo. El Trimestre Econômico, v. 25, n. 100, 1958. 